\title{
The Prognostic Value of the Metabolic Syndrome in Colon Cancer Patients
}

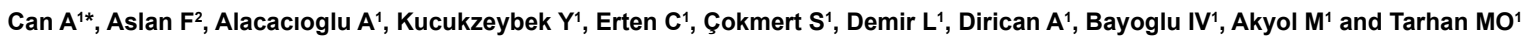

${ }^{1}$ Izmir Katip Celebi University Atatürk Training and Research Hospital Medical Oncology Clinic, Turkey

${ }^{2}$ Izmir Kâtip Celebi University Atatürk Training and Research Hospital Internal Medicine Clinic, Turkey

\begin{abstract}
Background: The aim of this study is to investigate the relationship between the Metabolic Syndrome the parameters of it and the manifest prognostic factors of the Colon Cancer in newly-diagnosed phase 2-4 colon cancer patients.

Patients and Method: 104 newly-diagnosed and phase 2-4 Colon Cancer patients were prospectively included in the study at İmir Atatürk Training and Research Hospital Medical Oncology Policlinic between June 2010 and December 2012. Demographic, anthropometric and laboratory data belonging to the patients were recorded. To detect the presence of Metabolic Syndrome at the time of the diagnosis, patients were tested for hunger blood glucose, LDL, HDL, triglyceride, total cholesterol levels besides the metric measurement of the waist and hip perimeters.

To detect the presence of hypertension, blood pressures were measured from both arms by a physician using a sphygmomanometer. Heights and weights of the patients were measured to calculate their BMI (Body Mass Index). The frequency of the Metabolic Syndrome was searched in colon cancer patients. The clinical phase, lymph node involvement, distant metastasis, histologic grade, perineural invasion and lymphovascular invasion were recorded. Frequency of the metabolic syndrome was looked into in colon cancer patients. The frequency of the Metabolic Syndrome parameters in colon cancer patients were looked into. Patients were divided into two groups as Colon Cancer patients with and without Metabolic Syndrome. Prognostic factors of the Colon Cancer were compared between these two groups.
\end{abstract}

Results: The average age of the patients included in the study was $61.67 \pm 10.09$ in those with Metabolic Syndrome and $58.45 \pm 10.39$ in those without Metabolic Syndrome. $47.1 \%$ of patients suffered from the Metabolic Syndrome. $61.2 \%$ and $38.8 \%$ of colon cancer patients with Metabolic Syndrome were female and male, respectively. Parameters of the Metabolic Syndrome revealed that manifest prognostic values (tumor size, lymph node involvement, metastatic status, tumor grade, differentiation, obstruction, perforation, perineural invasion, lymphovascular invasion, tumor localization) at the time of the diagnosis between the Colon Cancer patient groups with newly-diagnosed Metabolic Syndrome and those without the Metabolic Syndrome were not found to be statistically different.

Conclusions: In some of the former studies, it was found that the Metabolic Syndrome was negatively correlated with prognostic factors in Colon Cancer patients. Due to the insufficient number of patients, the lack of information on the duration of the Metabolic Syndrome in patients and the insufficient time for observation in our study, we were not able to draw clear-cut conclusions regarding the relationship between the newly-diagnosed colon cancer and the Metabolic Syndrome. Further research on this subject that includes higher number of patients is required.

Keywords: Colon cancer; Metabolic syndrome

\section{Introduction}

Colon Cancer is a significant health condition in developing as well as advanced countries. Colon Cancer is attributed to both genetic predisposition and environmental impacts. Environmental impacts are smoking, fat-rich nutrition, excess energy intake, physical inactivity and obesity (1/ 2-7). Recent epidemiological studies indicated that diabetes mellitus particularly increased the risk of proximal Colon Cancer by $40 \%-60 \%(1 / 12-13)$.

To make the diagnosis of the Metabolic Syndrome (MS), 3 positive NCEP-ATP III diagnostic criteria out of 5 are deemed sufficient: 1-Waist perimeter $>102 \mathrm{~cm}$ for males, $>88 \mathrm{~cm}$ for females. 2 - Triglyceride $>150$ $\mathrm{mg} / \mathrm{dl}$. 3-HDL being $<50 \mathrm{mg} / \mathrm{dl}$ for females and $<40 \mathrm{mg} / \mathrm{dl}$ for males. 4- Arterial blood pressure $>130 / 85 \mathrm{~mm} / \mathrm{Hg}$. 5- Hunger blood glucose $\geq 10 \mathrm{mg} / \mathrm{Hg}$. MS incidence increases in line with DM and obesity in both advanced and developing countries (1/ 10-12). Hyperinsulinemia and insulin resistance, which are the common characteristic of MS, $\mathrm{DM}$ and obesity were proved to play a considerable role in the Colon, Breast, Prostate and Endometrium Cancers (1/13-15). Some of the MS components were proved to increase the risk of Colon Cancer $(1 / 16$,
17). The aim of our study is to find out the correlation between the Metabolic Syndrome and the Colon Cancer.

\section{Material and Method}

\section{Patient selection}

This study is a mono-centered prospective research. 104 newlydiagnosed, phase 2-4 colon cancer patients were included in the study conducted between June 2010 and December 2011 at İzmir Katip

${ }^{*}$ Corresponding author: Can A, Izmir Katip Celebi University Atatürk Training and Research Hospital Medical Oncology Clinic, 35360 Izmir-Turkey, Tel: + 90232243 43 43; E-mail: drcanalper@gmail.com

Received June 04, 2014; Accepted September 27, 2014; Published September 30,2014

Citation: Can A, Aslan F, Alacacioglu A, Kucukzeybek Y, Erten C, et al. (2014) The Prognostic Value of the Metabolic Syndrome in Colon Cancer Patients. Intel Prop Rights 2: 129. doi:10.4172/2375-4516.1000129

Copyright: (c) 2014 Can A, et al. This is an open-access article distributed unde the terms of the Creative Commons Attribution License, which permits unrestricted use, distribution, and reproduction in any medium, provided the original author and source are credited. 
Çelebi University Atatürk Training and Research Hospital. Patients with evident diabetes mellitus and those who had chemotherapy before and second primary cancer were not included in the study.

\section{Research outline}

1- Glucose and lipid profiles were looked into in hunger blood sugar of patients prior to the chemotherapy. Waist perimeter, weight, height and blood pressures from both arms were measured by physicians.

2-For Metabolic Syndrome diagnosis: MS diagnoses were made for patients having NCEP-ATP III 3 positive diagnostic criteria out of 5 [1-3].

\section{Laboratory work}

Following minimum 8 hours of hunger, venous blood samples of patients were put into vacuum-sealed tubes with jelly content to run laboratory tests. After being kept in the room temperature for 30 minutes, they were centrifuged through 4000 revolutions per minute and routine biochemical tests were run. Kits belonging to the same firm were employed to look into the routine total cholesterol, HDL cholesterol, LDL glucose from the serums obtained using an Olympus 2700 autoanalyzer [4-7].

\section{Tumor phasing}

TNM Phasing System of the American Joint Committee on Cancer (AJCC) was used for the phasing of the patients. Tumor size (T), lymph node involvement $(\mathrm{N})$, presence of distant metastasis $(\mathrm{M})$.

\section{Instrument and method}

Prior to the start of this research, consent of the İzmir Katip Çelebi University Ethics Board was taken.

\section{Statistical analysis}

Statistical evaluation of the data was made by using 'SPSS 16.0 for Windows' package program. Comparison of groups' averages was made via the 'Mann-Whitney $U$ test', and the comparison of the ratios between groups was made via the 'Pearson chi-square test'. The P value being $<0.05$ was considered to be statistically significant [8-12].

\section{Results}

The study included 104 patients in total who are newly-diagnosed phase 2-4 colon cancer patients. 56 (54\%) of the patients were male, while $48(46 \%)$ were female. The average age of the patients was calculated as $60 \pm 10.3$. Those with the Metabolic Syndrome have the average age of $61.7 \pm 10.09$, and those without the Metabolic Syndrome were $58.5 \pm 10.4$, which are close results [13].

The frequency of the Metabolic Syndrome was found to be $47.1 \%$ (n:49) [14]. 61.2\% of the Colon Cancer patients with Metabolic Syndrome were female, while $38.8 \%$ were male. Demographic and clinical attributes of the patients included in the study are indicated in Table 1.

Among all the patients included in the study, 34\% had phase 2, while $29 \%$ had phase 3 , and $37 \%$ had phase 4 Colon Cancer. In terms of localization, the most frequent one was the tumor in the rectosigmoid with $41.3 \%$, while $30.8 \%$ of the patients had the tumor in the ascending colon, and $18.3 \%$ of them in the descending colon (Table 2).

At the end of the study, Colon Cancer patients were divided into two groups as those with (n:49) and without (n:55) the Metabolic Syndrome [15]. Statistical analysis was made between these two groups for prognostic factors (tumor size $(\mathrm{T})$, lymph node involvement $(\mathrm{N})$, metastatic status (M)) and tumor localization. The analysis did not produce any statistical difference between these two groups [16] (Tables 3-5).

The correlation between the Metabolic Syndrome and gender was statistically analyzed for newly-diagnosed colon cancers. The analysis showed statistically significant correlation between the Metabolic Syndrome and gender. $61.2 \%$ of Colon Cancer patients with the Metabolic Syndrome who were included in the study were female, while $38.8 \%$ of them were male. Female patients with Metabolic Syndrome had higher frequency of colon cancer $(\mathrm{p}:<0.05)($ Table 6$)$.

\begin{tabular}{|c|c|c|}
\hline & Patiens (n) & Rate(\%) \\
\hline \multicolumn{3}{|l|}{ SEX } \\
\hline Male & 56 & 54 \\
\hline Female & 48 & 46 \\
\hline Total & 104 & 100 \\
\hline \multicolumn{3}{|l|}{ TNM stage } \\
\hline II & 34 & 34 \\
\hline III & 28 & 29 \\
\hline IV & 37 & 37 \\
\hline Total & 99 & 100 \\
\hline \multicolumn{3}{|l|}{ Tumor size } \\
\hline $\mathrm{T} 2$ & 5 & 5,4 \\
\hline T3 & 64 & 69,6 \\
\hline $\mathrm{T} 4$ & 23 & 25 \\
\hline Total & 92 & 100 \\
\hline No & 51 & 55,4 \\
\hline N1 & 21 & 22,8 \\
\hline N2 & 20 & 21,7 \\
\hline Total & 92 & 100 \\
\hline MO & 66 & 64,1 \\
\hline M1 & 37 & 35,9 \\
\hline Total & 103 & 100 \\
\hline \multicolumn{3}{|l|}{ Localization } \\
\hline Unknown & 3 & 2,9 \\
\hline Rectum & 2 & 1,9 \\
\hline Assendan colon & 32 & 30,8 \\
\hline Transvers colon & 5 & 4,8 \\
\hline Desendan colon & 19 & 18,3 \\
\hline Rektosigmoid & 43 & 41,3 \\
\hline Total & 104 & 100 \\
\hline \multicolumn{3}{|l|}{ Metabolic syndrome } \\
\hline+ & 49 & 47,1 \\
\hline- & 55 & 52,9 \\
\hline Total & 104 & 100 \\
\hline
\end{tabular}

Table 1: Demographic and clinical characteristics of patients.

\begin{tabular}{|c|c|c|c|}
\hline Tumor localization & Metabolic synd (-) & Metabolic synd (+) & Total \\
\hline Unknown & 0 & 3 & 3 \\
\hline Rectum & 1 & 1 & 2 \\
\hline Assendan Colon & 18 & 14 & 32 \\
\hline Trasvers Colon & 5 & 0 & 5 \\
\hline Desendan Colon & 8 & 11 & 19 \\
\hline Recto-sigmoid & 23 & 20 & 43 \\
\hline Total & 55 & 49 & 104 \\
\hline
\end{tabular}

$X^{2}=8,85 p=0.115$

Table 2: The relationship between metabolic syndrome and tumor localization. 


\begin{tabular}{|c|c|c|c|c|}
\hline Metabolic syndrome & T2 N \% & T3 & T4 & Total \\
\hline Negative - & $2(40)$ & $33(50,8)$ & $13(56,5)$ & $49(100)$ \\
\hline Positive + & $3(60)$ & $32(49,2)$ & $10(43,5)$ & $44(100)$ \\
\hline Total & $5(5,4)$ & $65(69,9)$ & $23(24,7)$ & $93(100)$ \\
\hline
\end{tabular}

$X^{2}: 0,34 p: 0,844$

Table 3: The relationship between metabolic syndrome and tumor size (T)

\begin{tabular}{|c|c|c|c|c|}
\hline Metabolic syndrome & N0 (N \%) & N1(N\%) & N2 (N\%) & Total \\
\hline Negative - & $27(52,9)$ & $14(63,6)$ & $8(40)$ & $49(52,7)$ \\
\hline Positive + & $24(47,1)$ & $8(36,4)$ & $12(60)$ & $44(47,3)$ \\
\hline Total & $51(54,8)$ & $22(23,7)$ & $20(21,5)$ & $93(100)$ \\
\hline
\end{tabular}

$X^{2}: 2,35 p: 0,309$

Table 4: The relationship between metabolic syndrome and lymph node involvement(N).

\begin{tabular}{|c|c|c|c|}
\hline Metabolic syndrome & M0 (N \%) & M1(N\%) & Total \\
\hline Negative - & $34(50,7)$ & $21(56,8)$ & $55(52,9)$ \\
\hline Positive + & $33(49,3)$ & $16(43,2)$ & $49(47,1)$ \\
\hline Total & $67(64,4)$ & $37(35,7)$ & $104(100)$ \\
\hline
\end{tabular}

\section{$X^{2}: 035 p: 0,557$}

Table 5: The relationship between metabolic syndrome and distant metastases (M).

\begin{tabular}{|c|c|c|c|}
\hline Sex & Metabolic synd $(-)$ & Metabolic synd $(+)$ & Total \\
\hline Female & $18(37,5)$ & $30(62,5)$ & $48(100)$ \\
\hline Male & $37(66,1)$ & $19(33,9)$ & $56(100)$ \\
\hline Total & $55(52,9)$ & $49(47,1)$ & $104(100)$ \\
\hline
\end{tabular}

$X^{2}=8,468, p=0.004$

Table 6: Metabolic syndrome accordance with sex distribution.

\section{Discussion}

The objective of this study was to find out whether the Metabolic Syndrome and the Colon Cancer are related or not.

At the end of the research, no statistical difference was found in manifest prognostic values (tumor size, lymph node involvement, metastatic status) among newly-diagnosed Colon Cancer patients with and without Metabolic Syndrome Metabolic Syndrome at the time of the diagnosis [17].

According to the METSAR (Metabolic Syndrome Frequency Survey in Turkey) results conducted in 2004, in our country, the frequency of the metabolic syndrome was found to be $33.8 \%$ in 20 -year-old and older adults [18]. In our study, the frequency of the Metabolic Syndrome in Colon Cancer patients proved higher with 47.1\%. METSAR survey indicated that Metabolic Syndrome was more frequent in females compared to males $(41.1 \%$ in females, $28.8 \%$ in males). Our study gave out a similar conclusion as well. $61.2 \%$ and $38.8 \%$ of those patients with Metabolic Syndrome were female and male, respectively (p: <0.05) (Table 6).

The presence of the Metabolic Syndrome in the Colon Cancer was proved to increase both incidence and mortality in a great number of studies. In a study by Claudio et al. made in 2009 on 2256 male patients with Cholorecral Cancer, it was found that the metabolic syndrome was correlated with the colon cancer [19]. In a study by Zhanlong Shen et al., which was made in 2010, the Metabolic Syndrome was stated to be a prognostic indicator in the liver metastasis in the Colon Cancer and the relapse of the tumor [20]. In 2007, Han- Mo Chiu et al. underlined in their study that the Metabolic Syndrome was correlated to the bad prognosis in the Colon Cancer [21]. In a meta-analysis made by Katherine E. et al. in 2013, 11.465 Colon Cancer cases were evaluated in 17 studies. In this meta-analysis, the Metabolic Syndrome was highlighted as a factor that increased both the incidence of the Colon Cancer and mortality in males and females (meta-analysis) [22].

As a result, we would like to put forth the relationship among the Colon Cancer, one of the most frequently witnessed tumors and obesity, which is gradually getting more widespread and causing many diseases, and the Metabolic Syndrome, which is the underlying reason for bad prognosis in many types of cancer. Despite the presence of many researches revealing the negative relationship between the Colon Cancer and the Metabolic Syndrome in the literature, we did not come up with that sort of a negative relationship in our study due to the few number of patients and the short time for the follow-up.

\section{References}

1. Sokmen S (2004) Colorectal Cancerde Prognosis, Colorectal Special Issue. Turkey Clin Journal of Surgery 9: 57-65.

2. Lindmark G, Gerdin B (1994) Prognostic predictors in colorectal cancer. Dis Colon Rectum 37: 1219-27.

3. Kodner J, Robert DF, James WF (1999) Colon, rectum, anus. İn: Schwartz S, Shires T, Spencer F, Husser CW (Eds.). Principles of Surgery. New York: Mc Graw Hill Co, 1265-382.

4. Kusakcıoglu O (2003) Colorectal Cancer Diseases. Istanbul: Nobel Book Stores, 1-27.

5. Parkin DM, Pisani P, Ferlay J (1999) Global cancer statistic, CA Cancer. J Clin 49: 33-64.

6. Gonen O (2004) Epidemiology of Colorectal Cancer, Colorectal Special Issue Turkey Clin Journal of Surgery 9: 57-65.

7. Erarslan E, Türkay C (2007) Colorectal Cancer etiology and predisposing factors. Current Gastroenterology 11: 19-26.

8. Majerus E, Birnbaum E, Picus J (2002) Colorectal Malignancies. İn: Govindan $\mathrm{R}$, Arquette M (Eds.). The Washington Manual of Oncology. Philadelphia: Lippincott WW 191-202.

9. Norat T, Bingham S, Ferrari P, Slimani N, Jenab M, et al. (2005) Meat, fisch and colorectal cancer risk: the European Prospective Investigation into cancer and nutrition. J Natl Cancer 97: 906-916.

10. Giovannucci E, Ascherio A, Rimm EB, Colditz GA, Stampfer MJ, et al. (1995) Physical aktivity, obesity and risk for colon cancer and adenoma in men. Ann Intern Med 122: 327-334.

11. Skibber JM, Minsky BD, Hoff PM (2001) Cancer of the colon. In: DeVita VT, Hellman S, Rosenberg SA (Eds.). Cancer, Principles and Practice of Oncology. 6th ed. Philadelphia: Lipincott Williams and Wilkins, 1216-1271.

12. Nuako KW, Ahlquist DA, Mahoney DW, Schaid DJ, Siems DM, et al. (1998) Familial predisposition for colorectal cancer in chronic ulcerative colitis: a casecontrol study. Gastroenterology 115: 1079-83.

13. Gillen CD, Andrew HA, Prior P, Allan RN (1994) Crohn's Disease and colorecta cancer. Gut 35: 651-655

14. Winawer SJ, Zauber AG, Gerdes H, O'Brien MJ, Gottlieb LS, et al. (1996) Risk of colorectal cancer in the families of patient with adenomatous polyp. National Polyp Study Workgroup. N Engl J Med 334: 1339-1340.

15. Michell RJ, Ferrington SM, Dunlop MG, H Campbell (2002) Mismatch repair genes hMLH1 and hMSH2 and colorectal cancer. Am Epidermiol 156: 885-902.

16. Lagersstedt RK, Liu T, Vandrovcova J, Halvarsson B, Clendenning M, et al. (2007) Lynch syndrome (hereditary nonpolyposis colorectal cancer) diagnostics. J Natl Cancer Inst 99: 291-299.

17. Turunen MJ, Kivilaakso EO (1991) Increased risk of colorectal cancer after cholecystectomy. Ann Surg 194: 639-41.

18. Metabolic Syndrome Research Group. METSAR results. XX. National Congress of Cardiology. Antalya, 2004.

19. Claudio Pelucchi, Eva Negri, Renato Talamini (2010) Metabolic syndrome is 
Citation: Can A, Aslan F, Alacacıoglu A, Kucukzeybek Y, Erten C, et al. (2014) The Prognostic Value of the Metabolic Syndrome in Colon Cancer Patients. Intel Prop Rights 2: 129. doi:10.4172/2375-4516.1000129

Page 4 of 4

associated with colorectal cancer in men. Europan Juornal of Cancer 46: 18661872.

20. Shen Z, Ye Y, Bin L (2010) Metabolic syndrome is an important factor for the evolution of prognosis of colorectal cancer: survival, recurrence, and liver metastasis Am J Surg 200: 59-63.

21. Chıu HM, Lin JT, Shun CT, Liang JT, Lee YC, et al. (2007) Association of metabolic syndrome with proximal and synchronous colorectal neoplasm. Clin Gastroenterol Hepatol 5: 221-229.

22. Esposito K, Chiodini P, Capuano A (2013) Colorectal cancer association with metabolic syndrome and its components: a systematic review with metaanalysis. Endocrine 44: 632-647. 